\title{
Having fewer hospital beds does not mean less health care
}

Lynn Eaton London

The number of beds in NHS hospitals may be falling, but that doesn't mean the amount of health care provided has been reduced, argues the NHS Confederation in a briefing paper it issued this week.

The briefing from the confederation, which represents NHS trusts in England, Wales, and Northern Ireland, is the first in a series aiming to debunk some of the popular myths surrounding the most contentious issues in the NHS.

"We need to move away from this fixation with bricks and mortar," said Gill Morgan, chief executive of the confederation. "The world is changing, patients' needs are changing, and the NHS is adapting to meet those needs.

"More patients are being treated faster and more effectively than ever before by the NHS. The number of actual beds has steadily reduced, yet the amount of care the service is able to deliver has dramatically increased."
The number of beds has fallen consistently-by $40 \%$ since 1959, as new technologies and ways of treatment have come into being.

"We must start judging the NHS by the number of people we make better and keep well, not by the amount of beds which are, after all, only hospital furniture," Dr Morgan said. "Developments in technology and changes in the way treatment is delivered mean we simply need fewer beds."

Since 1984, when hospitals in England had 211617 hospital beds, the number has fallen by $31 \%$, to 145218 .

In 2004/5 there were 109505 acute beds (a decrease from 138848 in 1984), 26619 geriatric beds (from 55 571) and 9095 maternity beds (from 17 189).

The report outlines examples of new approaches to care that mean it is no longer necessary to have as many hospital beds. These include:

- Advances in treatments such

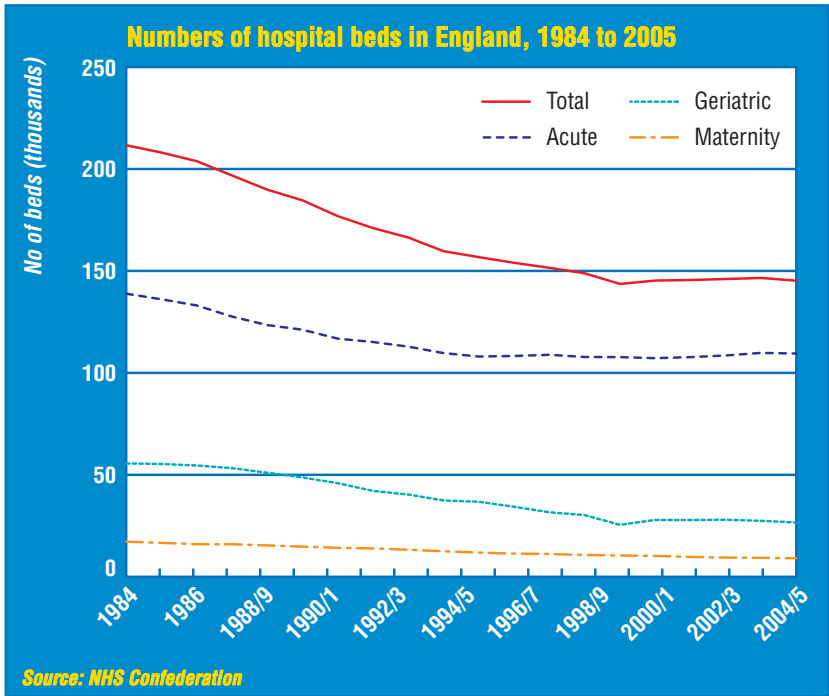

as chemotherapy that have enabled patients to be treated in their own homes

- Admitting patients on the day of their operation and ensuring that they don't have to wait days for the consultant's weekly ward round before they can be discharged
- Providing some procedures, such as vasectomy or endoscopy, in the community

- Technological advances, such as angioplasty for heart disease, and keyhole surgery.

Why We Need Fewer Hospital Beds is available at www.nhsconfed.org.

\section{Attorney general is to intervene in case of expert witness immunity}

Clare Dyer legal correspondent, BMJ

The attorney general, the senior law officer for England and Wales, is to intervene in the General Medical Council's forthcoming appeal against a high court ruling that expert witnesses are immune from disciplinary proceedings over their courtroom evidence.

Lord Goldsmith has asked the Court of Appeal for permission to argue at the hearing, which starts on 10 July, that giving witnesses immunity would be against the public interest.

Mr Justice Collins ruled last
February that Roy Meadow, the retired paediatrician who gave misleading statistical evidence at the trial of Sally Clark for the murder of her two baby sons, should never have been brought before the GMC, let alone found guilty of serious professional misconduct and ordered to be struck off the medical register (BMJ 2006;332:439).

The judge held that witness immunity, the rule that witnesses are immune from being sued over their evidence in court, also applies to disciplinary proceed- ings-except for the rare case where a judge reports the expert to the disciplinary body.

He said the rule was necessary if expert witnesses were not to be deterred from giving evidence.

Mrs Clark's conviction was later quashed, partly because of Professor Meadow's evidence but mainly because the Home Office pathologist who carried out autopsies on both babies had failed to disclose microbiological findings from one baby that could have pointed to a death from natural causes. Mrs Clark's father filed a complaint against Professor Meadow with the GMC.

Lord Goldsmith said of Mr Justice Collins's ruling: "I think that decision is wrong in principle. I think the public does deserve a degree of protection from people who go to extremes and go beyond their field of expertise or give views which are not properly supported."

Whatever the outcome of the appeal Professor Meadow will remain cleared of serious professional misconduct, because the appeal will focus solely on the immunity point.

Lord Goldsmith, who said he might argue the case personally in court if other commitments permitted, added: "I am not taking sides over whether Professor Meadow was or was not guilty of serious professional misconduct.

"I am concerned with the question of whether someone who goes to court and gives expert evidence should be immune from action by disciplinary bodies." 